\title{
Rare Case of Mycetoma Foot without any Discharging Sinuses: A Case Report
}

\author{
Dr. Ashwini Sankhe ${ }^{1}$, Dr. Jernail Singh Bava², Dr. Swapnil Patil ${ }^{3}$, Dr. Kiran Kale ${ }^{4}$ \\ ${ }^{1}$ Assistant Professor, Department of Radiology, LTMMC and GH - Sion, Mumbai, Maharashtra, India \\ ${ }^{2}$ Professor, Department of Radiology, LTMMC and GH - Sion, Mumbai, Maharashtra, India \\ ${ }^{3}$ Resident, Department of Radiology, LTMMC and GH - Sion, Maharashtra, India \\ ${ }^{4}$ Resident, Department of Radiology, LTMMC and GH - Sion, Mumbai, Maharashtra, India
}

\begin{abstract}
Mycetoma is a type of a slowly progressive chronic subcutaneous infection caused by actinomycetes or true fungi. A local trauma like cut or splinter can cause the infection leading to a granulomatous reaction. Infection tracks through skin, facial planes and can sometimes involve the underlying bone. Most commonly the foot is involved but also hands, back or shoulders can be involved.A 43 year old male, with ankle and foot swelling, with no discharging sinuses was studied at our institute. Initially, provisional diagnosis of tuberculous osteomyelitis was made, which latter turned out be mycetoma.
\end{abstract}

Keywords: Dot-in-circle, Mycetoma, discharging sinus, culture, non-farmer

\section{Introduction}

Mycetoma or Madura foot is a chronic granulomatous infection of the epidermis as well as the dermis caused by the bacteria namely Actinomyces (Actinomycetoma) $60 \%$ or by true fungi (eumycetoma like madurellamycetomatis or pseudallescheriaboydii) $40 \%$.

The management of these two groups is totally different, so it is very important to distinguish between these two etiologies. This infection results in a granulomatous inflammatory response in the subcutaneous tissue and dermis, which can also extend to the underlying bone and can cause sinuses late in the course of disease.Discharging sinuses are characteristic of mycetoma [1]. Here we present an atypical and interesting case of a young non-diabetic male, with no discharging sinuses, non-farmer by occupation, in whom mycetoma was not suspected initially, but latter MRI and histopathology played an important role in diagnosis.

\section{Case History}

A 43 year old male, police inspector by profession, residing in the city of Mumbai presented with soft tissue swelling of his left ankle and foot since 12-15 months. There were no clinical signs of inflammation, ulceration, discharge or sinuses. [Figure 1-2: Swelling over foot]

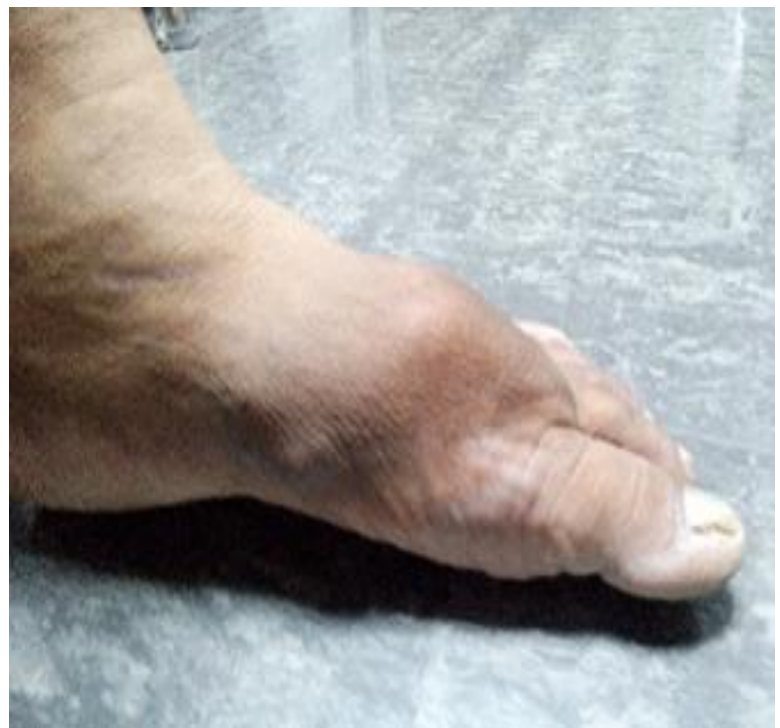

Figure 1

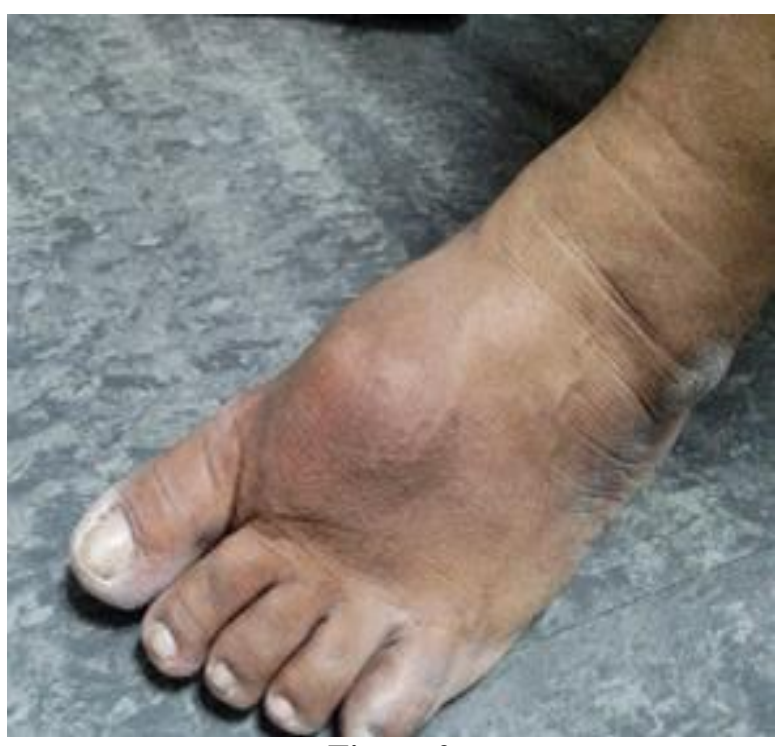

Figure 2 


\section{International Journal of Science and Research (IJSR) \\ ISSN (Online): 2319-7064 \\ Index Copernicus Value (2013): 6.14 | Impact Factor (2014): 5.611}

Radiograph revealed minimal bony erosions. USG of the patient was done which revealed well defined hypoechoic lesions with central hyperechoic foci. However, there was no vascularity noted in these lesions. There was no surrounding inflammation. [Figure 3-4: Well-defined hypoechoic lesion (long arrow) with central hyperechoic focus (short arrows)]

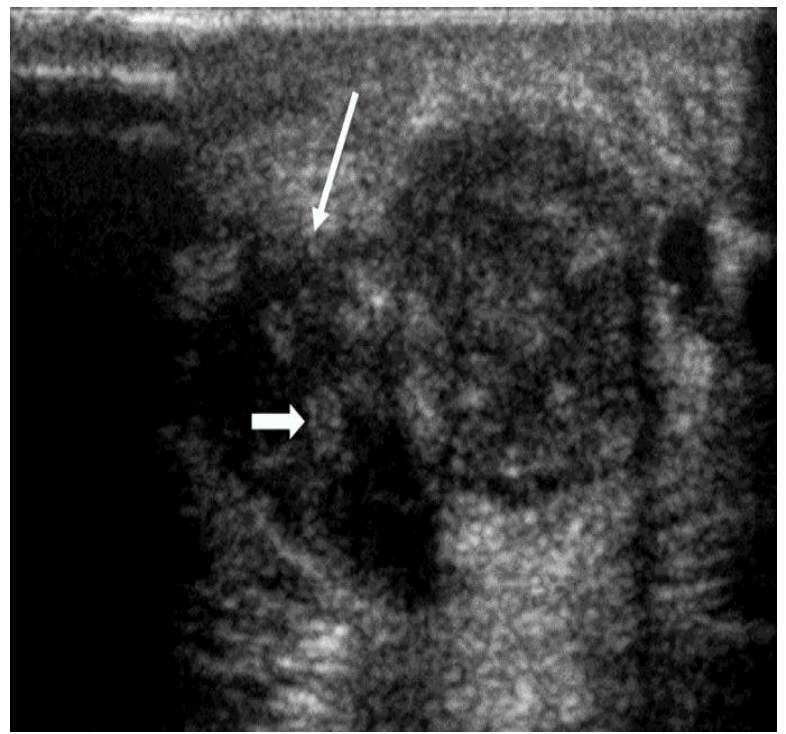

Figure 3

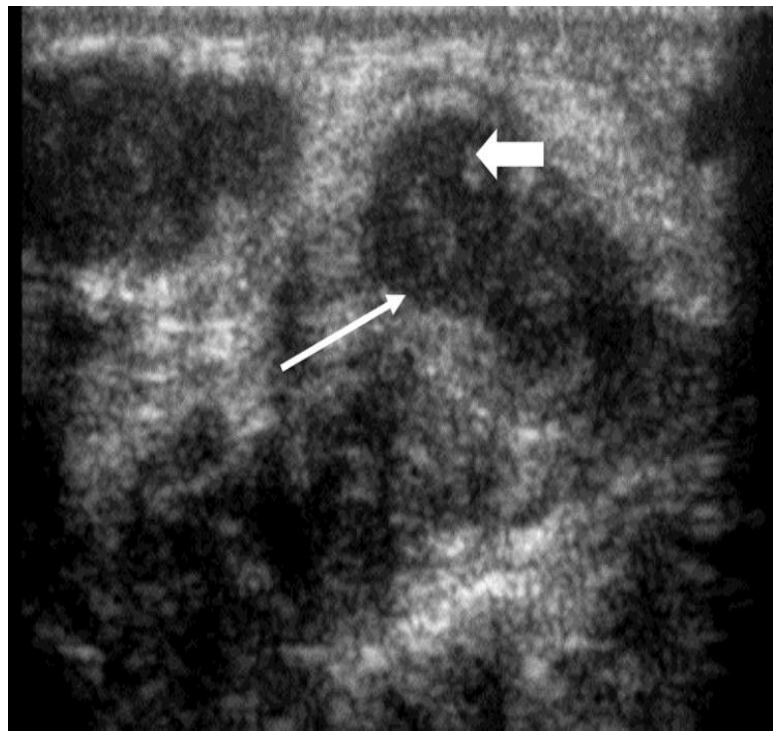

Figure 4

Provisional diagnosis of tuberculous osteomyelitis was made as tuberculous infection is quite common in this part of the world; the patient was started on anti-tuberculous treatment for 6 months. However, there was no relief of symptoms and the swelling was persistent.MRI was advised by the physician as anti-tuberculous treatment was ineffective. Accordingly, 3T MRI was done which revealed multiple varying sized lesions appearing hyperintense on T2WI and STIR, isointense on T1WI with heterogeneous contrast enhancement predominantly in the subcutaneous plane [Figure 5 (a-b-c-d) shows "Dot-in-circle" lesions (long arrows) in the soft tissue. Axial STIR (a) and sagittal T2W MRI image (b) through the sole of the foot show multiple bright round lesions with a central dot (short arrows); T1 Axial (c) shows hypodense lesions (black arrows). Post contrast (d) images show heterogeneous enhancement (black arrows)]

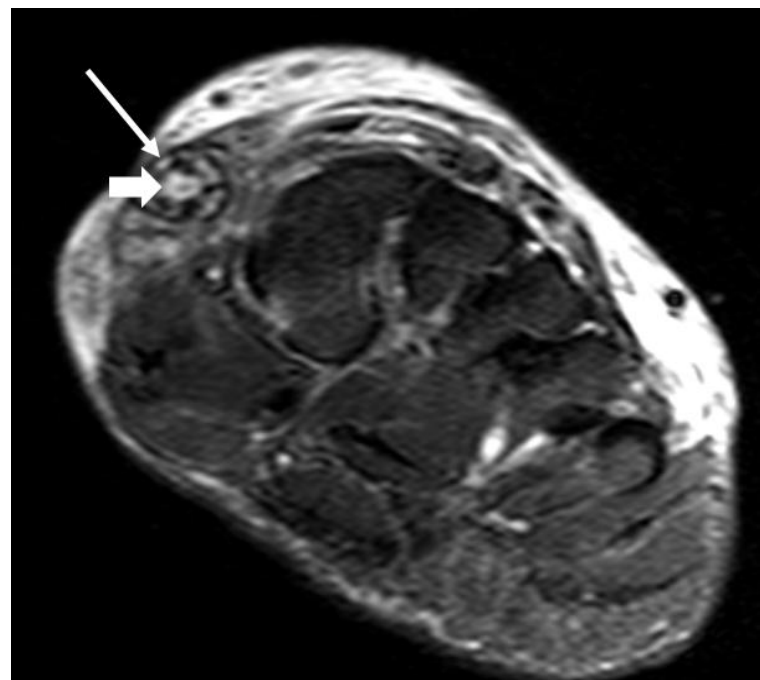

Figure 5(a)

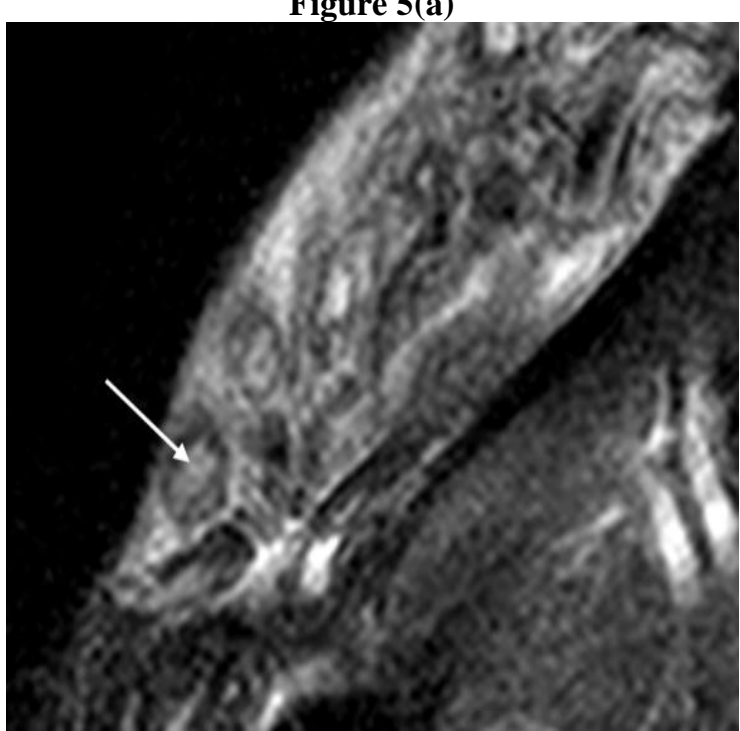

Figure 5(b)

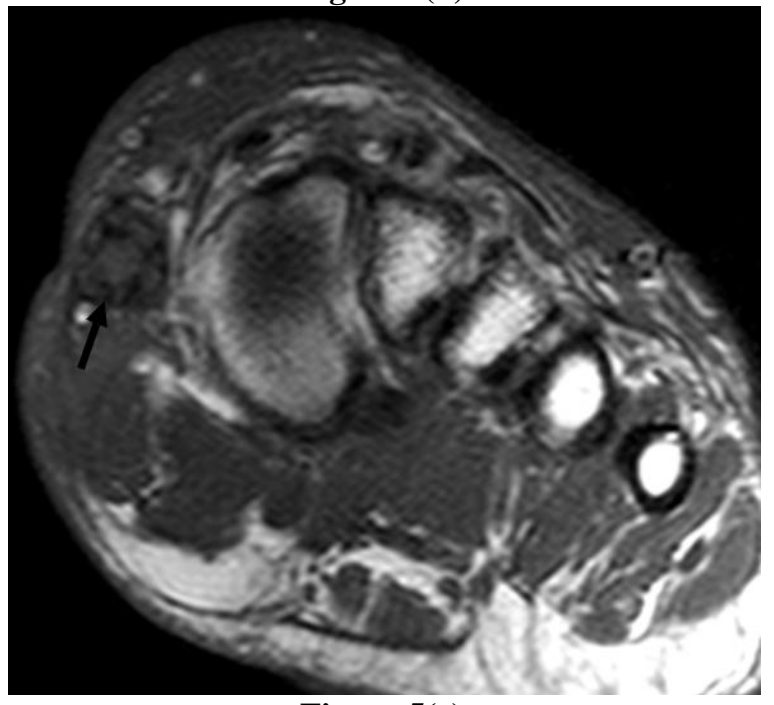

Figure 5(c) 


\section{International Journal of Science and Research (IJSR) \\ ISSN (Online): 2319-7064}

Index Copernicus Value (2013): 6.14 | Impact Factor (2014): 5.611

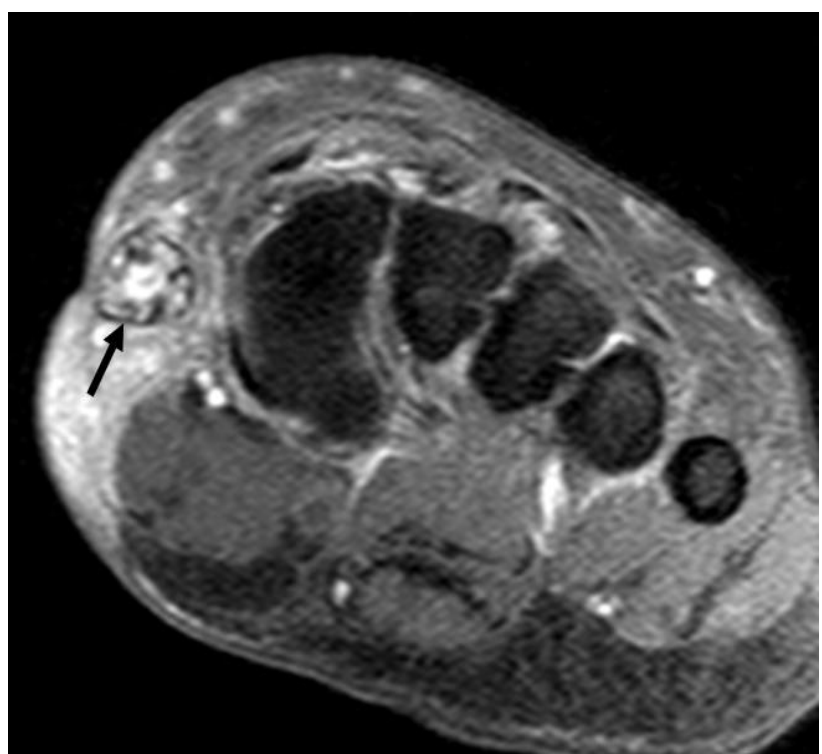

Figure 5(d)

Few of these lesions show central T2 hypointense foci, with few other showing marked peripheral blooming on GRE images. A provisional diagnosis of mycetoma was made based on the well known dot-in-circle sign. Fine needle aspiration cytology (FNAC) was done by aspiration, using a syringe. Aspirate was sero-sanguinous and pus like.Histology report revealed fibrocollagenous tissue with proliferating capillaries,mixed inflammation and occasional fungal colonies surrounded by granulomatous inflammation. It was neagative for AFB and Gram stain.

Cytological diagnosis confirmed mycetoma infection[Figure 6 (a-b) fungal colonies]

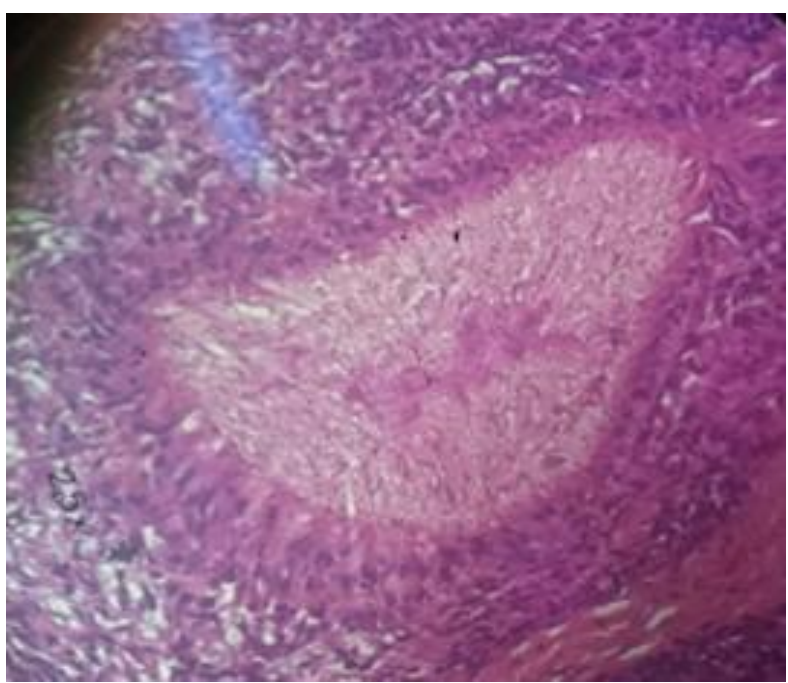

Figure 6(a)

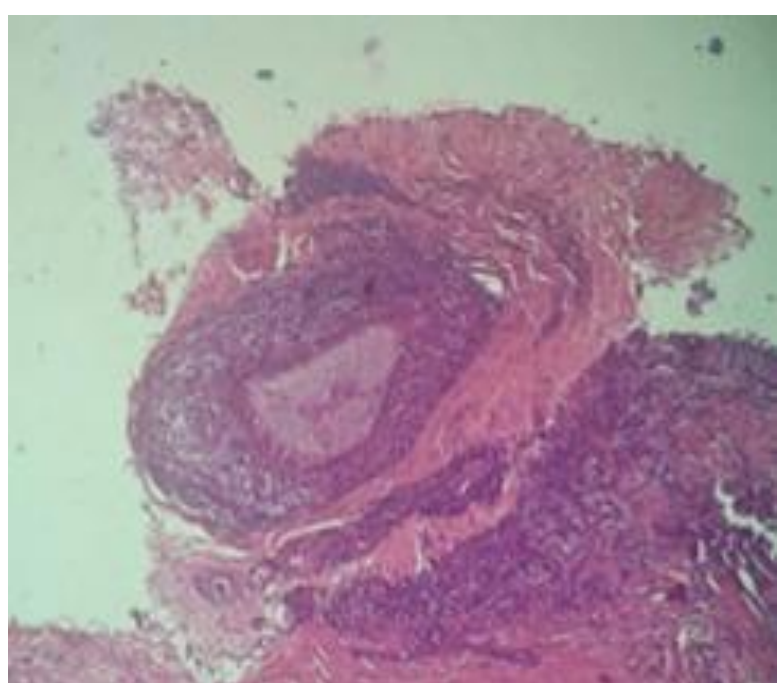

Figure 6(b)

Further, excision biopsy specimen confirmed the diagnosis of eumycetoma.

\section{Discussion}

Mycetoma or Madura foot is a chronic granulomatous infection of the epidermis as well as the dermis caused by the bacteria actinomycosisor by true fungi. It was first described in the Indian district of Madura in 1846, hence also known as Madura foot. The incubation period varies from weeks to several years.Penetration of the skin with a sharp object like a thorn causes the infecting organism to directly inoculate inside. Hence indivuduals with occupation like farming who have to work bare foot are more prone to the infection. Initially, patients present with a painless subcutaneous nodule followed by fistulae, from which a purulent exudate along with some granules may discharge. Sinuses seldom develop before 3 months; but about onethird of patients have discharging sinuses by 3 to 6 months and nearly all patients have sinuses by the end of one year [2]. Actinomycotic mycetoma is caused by aerobic species of actinomycetes like Nocardia Streptomyces and Actinomadura. Eumycotic mycetoma is caused by variety of fungi, the most common being Madurella mycetomatis, Pseudoallescheria boydii and Acremonium species [3].Infection begins in the skin and subcutaneous tissue causing nodular or papular swelling which grows and ruptures forming discharging sinuses which exude characteristic coloured grains [4]. In our patient, there were no discharging sinuses. This was an atypical presentation of mycetoma. Similar cases of mycetoma without discharging sinuses were reported separately by Hay et al.[5] and Sudipta Saha et al. [6]. In the treatment of mycetoma, antibiotic or antifungal like Fluconazole is used, whereas surgery is done in special cases [7] especially for eumycetoma lesions in the extremities [8]. In few selected cases external beam radiotherapy in doses ranging from 3.5-14 Gy has been considered successful [9].

\section{Conclusion}

This is an interesting presentation of mycetoma where there are no discharging sinuses as well as the occupation is atypical. Mycetoma was probably not suspected clinically 


\section{International Journal of Science and Research (IJSR) \\ ISSN (Online): 2319-7064}

Index Copernicus Value (2013): 6.14 | Impact Factor (2014): 5.611

and MRI played an important role in making the diagnosis; confirmed with histopathology. In endemic areas, mycetoma/Madura foot should be considered in the differential diagnosis of chronic subcutaneous lesions, even in the absence of sinuses or discharging grains, as surgical excision of such lesions may result in complete cure.

\section{References}

[1] Zaias N, Taplin D, Gerbert. Mycetoma. Arch Dermatol 1969; 99:215-25.

[2] McGinnis. Mycetoma. Dermatology Clin 1996; 41:97104.

[3] Iffat H, Abid K. Mycetoma Revisited. N Dermatol Online, 2011; 2(3): 147-150.

[4] Mohammad N, Arif C, Ruksana P, Rokon U, Abdur R, Moydul H; The Madura foot. A Case Report. N Dermatol Online, 2011; 2(2): 70-73.

[5] Hay RJ, Mackenzie DW. Mycetoma in UK: A survey of forty-four cases. ClinExpDermatol 1983; 8:553-62.

[6] Saha S, Dhar A, Karak AK. Mycetoma sans sinuses. Indian J DermatolVenereolLeprol 2006; 72:143-4.

[7] Venkatswami S, Sankarasubramanian A, Subramanyam S. The madura foot: looking deep. Int J Low Extrem Wounds. 2012;1:31-42

[8] Ahmed AA, van de Sande WW, Fahal A, et al. Management of mycetoma: major challenge in tropical mycoses with limited international recognition. CurrOpin Infect Dis. 2007; 20(2):146-51.

[9] Falkson C, Sur R, Pacella J. External beam radiotherapy: a treatment option for massive haemoptysis caused by mycetoma. ClinOncol (R CollRadiol). 2002;14(3):233-5 